Yang Zhang, Lingling Zhu*, Liugang Chen, Luoqiang Liu, and Guotian Ye

\title{
Influence of Magnesia on Demoulding Strength of Colloidal Silica-Bonded Castables
}

https://doi.org/10.1515/rams-2019-0008

Received Sep 24, 2018; accepted Dec 15, 2018

\begin{abstract}
The change in demoulding strength of colloidal silica-bonded castables with and without magnesia is investigated with emphasis on the relationship between the demoulding strength and chemical bond changes. It was confirmed that the demoulding strength was raised with the presence of magnesia in colloidal silica-bonded castables because of the increased chemical bonding between the sol particles. The X-ray photoelectron spectroscopy (XPS) and the Fourier transformation infrared spectroscopy (FTIR) results indicate the formation of new $\mathrm{Si}-\mathrm{O}-\mathrm{Mg}$ chemical bond from the decreased $\mathrm{O} 1 s$ and $\mathrm{Si}$ $2 p$ binding energy, and the appearance of weak vibration peaks at 668 and $419 \mathrm{~cm}^{-1}$ in the spectrum of colloidal silica with the addition of $\mathrm{MgO}$ after curing at $30^{\circ} \mathrm{C}$ for 24 hours. The reaction between colloidal silica and magnesia could promote the formation of $-\mathrm{Si}-\mathrm{O}-\mathrm{Mg}-\mathrm{O}-\mathrm{Si}-$ bonds, which is the primary reason for the demoulding strength improvement.
\end{abstract}

Keywords: chemical bond change; demoulding strength; colloidal silica-bonded castables; magnesia

\section{Introduction}

Colloidal silica-bonded castables have advantages over low cement or hydratable alumina-bonded castables in terms of drying performance, sintering properties, low

\footnotetext{
*Corresponding Author: Lingling Zhu: Henan Key Laboratory of High Temperature Functional Ceramics, School of Materials Science and Engineering, Zhengzhou University, Zhengzhou 450001; Email: llzhu@zzu.edu.cn; Fax: +86-371-67781590

Yang Zhang, Luoqiang Liu, Guotian Ye: Henan Key Laboratory of High Temperature Functional Ceramics, School of Materials Science and Engineering, Zhengzhou University, Zhengzhou 450001 Liugang Chen: Henan Key Laboratory of High Temperature Functional Ceramics, School of Materials Science and Engineering, Zhengzhou University, Zhengzhou 450001; Department of Materials Engineering, KU Leuven, Kasteelpark Arenberg 44, Leuven, 3001, Belgium
}

¿ Open Access. ( 2019 Y. Zhang et al., published by De Gruyter. License and intermediate temperature strength and volume stability [1-7]. However, the colloidal silica-bonded castables have not been as widely used as calcium aluminate cement (CAC)-bonded castables because the green mechanical strength of colloidal silica-bonded castables is very low compared to the hydraulic bonded-ones [4]. The strength of the former castables develops sluggishly during curing because the slow condensation reaction of $\mathrm{Si}-\mathrm{OH}$ between $\mathrm{SiO}_{2}$ particles $\left(\mathrm{Si}-\mathrm{OH}+\mathrm{HO}-\mathrm{Si}=\mathrm{Si}-\mathrm{O}-\mathrm{Si}+\mathrm{H}_{2} \mathrm{O}\right)$ lead to very low green strength of the green strength of the castables $[2,4,8,10]$.

In recent years, increasing researches have been done to enhance the green strength of colloidal silica-bonded castables. For example, it was reported that the demoulding strength of colloidal silica-bonded high alumina castables was increased with the reducing curing humidity [2, 9]. In particular, various additives have been introduced into colloidal silica-bonded castables to promote the demoulding strength $[5,6,8,10,11]$. CAC and magnesium oxide (MgO) are commonly used as gelling agents to improve the demoulding strength of colloidal silica-bonded castables $[5,6]$. However, the presence of $\mathrm{CaO}$ from CAC can be deleterious to the high-temperature properties of the alumina-based castables with colloidal silica, because $\mathrm{CaO}$ can result in the formation of low-melting temperature phases, such as gehlenite $\left(2 \mathrm{CaO} \cdot \mathrm{Al}_{2} \mathrm{O}_{3} \cdot \mathrm{SiO}_{2}\right.$, melting point $\left.(\mathrm{mp})=1590{ }^{\circ} \mathrm{C}\right)$ or anorthite $\left(\mathrm{CaO} \cdot \mathrm{Al}_{2} \mathrm{O}_{3} \cdot 2 \mathrm{SiO}_{2}, \mathrm{mp}\right.$ $\left.=1550^{\circ} \mathrm{C}\right)[12,13]$. It has been proposed that $\mathrm{MgO}$ addition is favourable to raise the green strength of colloidal silicabonded castables because $\mathrm{Si}-\mathrm{O}-\mathrm{Mg}$ bonds will form from the released $\mathrm{Mg}^{2+}$ ions and the broken $\mathrm{Si}-\mathrm{O}$ bonds on the surface of silica particles during the placement and curing processes [7, 14]. However, the cause of the increased demoulding strength through the viewpoint of the new bond formation (-Si-O-Mg-O-Si-) has not been substantiated. This work examines the effect of magnesia on demoulding strength of colloidal silica-bonded castables and on the chemical bond formation of silica particles using XPS and FTIR, with the aim of establishing the relationship between demoulding strength and the change in chemical bonds between $\mathrm{SiO}_{2}$ particles of colloidal silica caused by the presence of magnesia. 
Table 1: Formulation of colloidal silica-bonded castables with and without magnesia.

\begin{tabular}{|c|c|c|c|c|c|}
\hline \multicolumn{2}{|r|}{ Raw materials } & \multirow{2}{*}{$\begin{array}{c}\text { CSO (wt.\%) } \\
20\end{array}$} & \multirow{2}{*}{$\frac{\text { CS1 (wt. \%) }}{20}$} & \multirow{2}{*}{$\frac{\text { CS3 (wt. \%) }}{20}$} & \multirow{2}{*}{$\frac{\text { CS5 (wt.\%) }}{20}$} \\
\hline & $6-3 \mathrm{~mm}$ & & & & \\
\hline Tabular & 3-1 mm & 30 & 30 & 30 & 30 \\
\hline \multirow[t]{2}{*}{ corundum } & $1-0 \mathrm{~mm}$ & 20 & 20 & 20 & 20 \\
\hline & $\leq 0.044 \mathrm{~mm}$ & 24 & 24 & 24 & 24 \\
\hline Reactive alumina & CL370 & 6 & 6 & 6 & 6 \\
\hline Dispersant & Sodium hexametaphosphate & 0.1 & 0.1 & 0.1 & 0.1 \\
\hline Binder & Colloidal silica & 6.6 & 6.6 & 6.6 & 6.6 \\
\hline Gelling agent & Magnesia & - & 0.1 & 0.3 & 0.5 \\
\hline
\end{tabular}

\section{Experimental}

The colloidal silica-bonded castables were composed of different-sized aggregates of tabular corundum (Almatis), reactive alumina (CL370, Almatis) and colloidal silica $\left(\mathrm{SiO}_{2} \geq 30\right.$ wt.\%, $\mathrm{pH}=8.9$, Yuda chemical Co.) (Table 1). Sodium tripolyphosphate was used as dispersant for the castable. In order to investigate the effect of magnesia on the demoulding strength of colloidal silica-bonded castables, different amounts (0, 0.1, 0.3 and 0.5 wt.\%) of fused magnesia $(\mathrm{MgO} \geq 97.19 \mathrm{wt} . \%, \leq 0.074 \mathrm{~mm})$ were added as gelling agent.

The castables were firstly dry-mixed for 1 minute, and then followed by 2 minutes wet mixing with colloidal silica in a laboratory mixer. After that, the mixtures were cast in $40 \mathrm{~mm} \times 40 \mathrm{~mm} \times 160 \mathrm{~mm}$ molds under vibration. After curing in the molds for 24 hours at $30^{\circ} \mathrm{C}$, the samples were de-molded, and the cold crushing strength (CCS) and cold modulus of rupture (CMOR) of the castable samples were tested.

In order to study the influence of magnesia on the chemical bond changes between colloidal silica, the samples of colloidal silica with and without magnesia were prepared. Both colloidal silica and magnesia were separately kept at $30^{\circ} \mathrm{C}$ for 24 hours in advance, and then colloidal silica and the mixture of colloidal silica with of 0.5 wt.\% magnesia were agitated with a magnetic stirrer for 2 minutes. After curing at $30^{\circ} \mathrm{C}$ for 24 hours, the as-prepared samples were rapidly frozen at $-50^{\circ} \mathrm{C}$ for 1.5 hours, and then dried in a vacuum box under a pressure of $60 \mathrm{~Pa}$ at $20^{\circ} \mathrm{C}$ for 24 hours to remove the water. The microstructure differences of the samples were observed by FESEM (JSM-7500F, JEOL, Tokyo, Japan), and the chemical bonding change was detected by XPS (Amicus, Kratos, Manchester, UK) through the shift of $\mathrm{O} 1 s$ and $\mathrm{Si} 2 p$ binding energy, and FTIR (Nicolet iS 50, Thermo Fisher, USA) through the presence of $\mathrm{Si}-\mathrm{O}-\mathrm{Mg}$ vibration and shift of $\mathrm{Si}-\mathrm{O}-\mathrm{Si}$ vi- bration. Furthermore, the FTIR analysis has been carried out over the frequency range of $4000-400 \mathrm{~cm}^{-1}$.

\section{Results and Discussion}

Figure 1 shows the demoulding strength of colloidal silicabonded castables with and without magnesia after curing at $30^{\circ} \mathrm{C}$ for 24 hours. As shown in Figure 1, both CMOR and CCS of the colloidal silica-bonded castables are improved by the increase of magnesia addition. For example, the CMOR of the castable with $0.5 \mathrm{wt} . \%$ magnesia (CS5, 1.7 $\mathrm{MPa}$ ) is significantly higher in comparison with that of the castable without magnesia (CSO, 0.8 MPa). Similarly, the CCS of the castable with magnesia (CS5, 10.2 MPa) is considerably higher than that of the castable without magnesia (CSO, 6.1 MPa). The above results demonstrate that the addition of magnesia favors the demoulding strength of the colloidal silica-bonded castables.

Figure 2 presents the microstructure of colloidal silica with and without magnesia after curing for 24 hours at $30^{\circ} \mathrm{C}$. The morphology of the silica sol significantly changed with the addition of $0.5 \mathrm{wt} . \%$ magnesia after curing for 24 hours at $30^{\circ} \mathrm{C}$. It is seen that pure colloidal silica is composed of mono-dispersed $\mathrm{SiO}_{2}$ particles with the size of $20 \mathrm{~nm}$ (Figure 2a); while $\mathrm{SiO}_{2}$ colloidal particles are partially agglomerated together with the addition of 0.5 wt.\% magnesia (Figure 2b). The above results indicate that the addition of magnesia promotes the adhesion of $\mathrm{SiO}_{2}$ colloidal particles, which may help accelerate the condensation of colloidal silica.

Referring to the promoted adhesion of $\mathrm{SiO}_{2}$ colloidal particles (as shown in Figure 2b) in colloidal silica with addition of magnesia after curing at $30^{\circ} \mathrm{C}$ for 24 hours, the influence of magnesia on the condensation of colloidal silica was examined by XPS to detect if any new chemical bonds could be formed in colloidal silica with $\mathrm{MgO}$. According to 

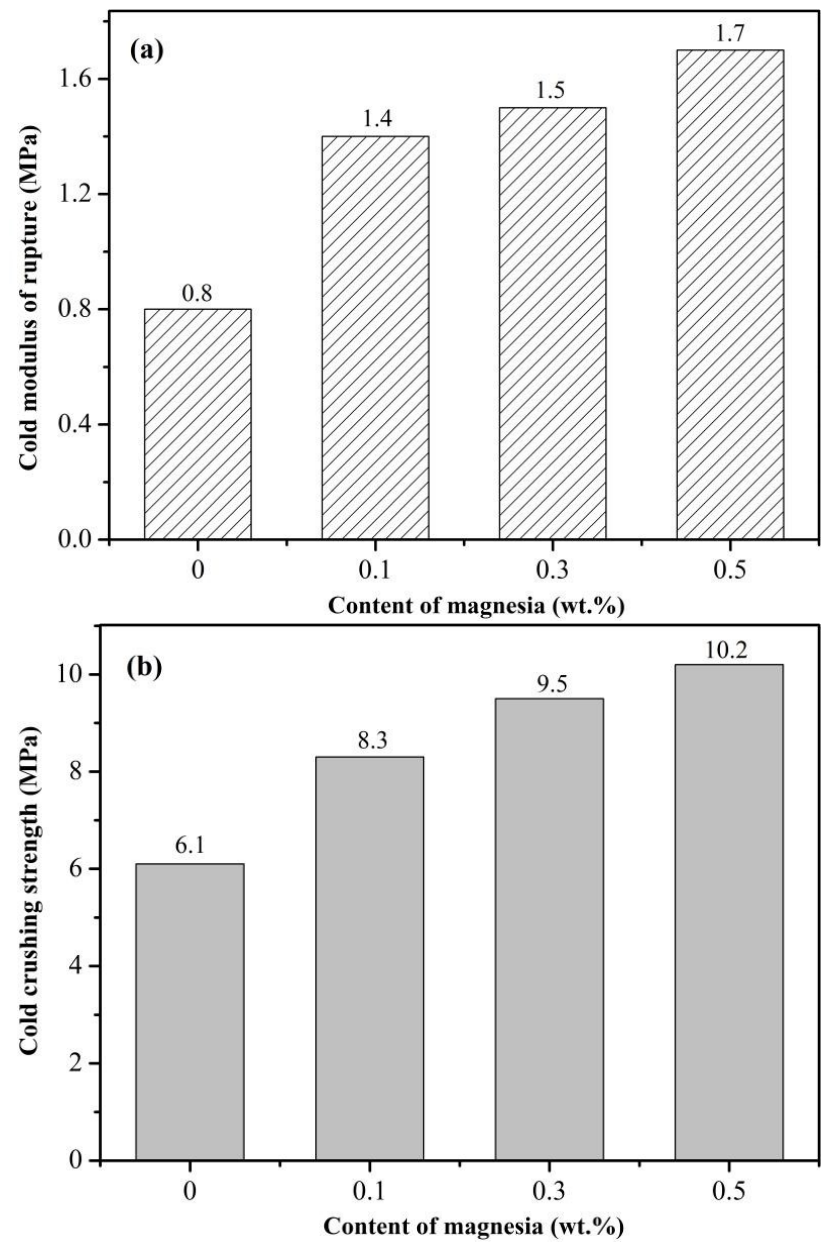

Figure 1: CMOR and CCS of colloidal silica-bonded castables with and without magnesia cured at $30^{\circ} \mathrm{C}$ for 24 hours.

the XPS spectra of colloidal silica with and without magnesia shown in Figure 3, characteristic peaks corresponding to $\mathrm{Mg} 1 \mathrm{~s}(1302 \mathrm{eV}), \mathrm{Mg} 2 p(74 \mathrm{eV})$ and Mg KLL auger are present in the XPS spectrum of colloidal silica with the addition of $0.5 \mathrm{wt} . \%$ magnesia after curing at $30^{\circ} \mathrm{C}$ for 24 hours. In order to figure out the $01 s$ and $\mathrm{Si} 2 p$ binding energy (BE) changes in colloidal silica with the addition of $0.5 \mathrm{wt} . \%$ magnesia, $01 \mathrm{~s}$ and Si $2 p$ XPS spectra for colloidal silica with and without magnesia, and the peak fitting of $\mathrm{O} 1 \mathrm{~s}$ spectrum for colloidal silica with $0.5 \mathrm{wt} . \% \mathrm{MgO}$ are analyzed.

As shown in Figure 4 (a) and (b), the 01 s BE (532.60 $\mathrm{eV}$ ) and $\mathrm{Si} 2 p \mathrm{BE}(103.20 \mathrm{eV})$ in colloidal silica with $0.5 \mathrm{wt} . \%$ magnesia are lower than the $\mathrm{O} 1 s \mathrm{BE}(532.85 \mathrm{eV})$ and $\mathrm{Si} 2 p$ $\mathrm{BE}(103.65 \mathrm{eV})$ in colloidal silica, indicating the formation of $\mathrm{Si}-\mathrm{O}-\mathrm{Mg}$ bonds in colloidal silica with magnesia. Because $\mathrm{Mg}$ is less electronegative than $\mathrm{H}$, and consequently, the substitution of $\mathrm{H}$ (2.1) in $\mathrm{Si}-\mathrm{OH}$ by $\mathrm{Mg}$ (1.2) would decrease the O1s BE in $\mathrm{Si}-\mathrm{O}-\mathrm{Mg}$ bonds, due to the increase of
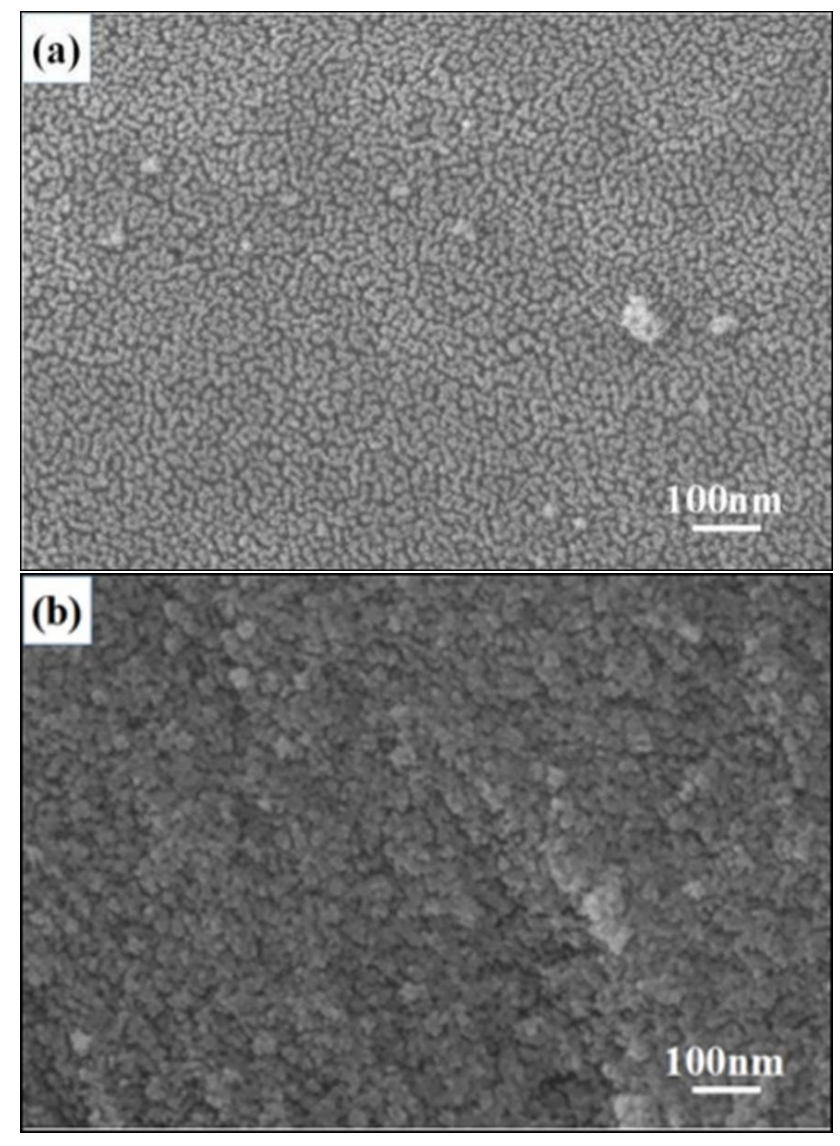

Figure 2: SEM photograph of colloidal silica without (a) and with $\mathrm{MgO}$ (b) after curing for 24 hours at $30^{\circ} \mathrm{C}$.

O outer electron density [15-17]. And then the outer electron density of Si would increase $[15,16]$ because of the covalence of $\mathrm{Si}-\mathrm{O}$ bond, resulting in the decrease of $\mathrm{Si} 2 p$ $\mathrm{BE}$ in $\mathrm{Si}-\mathrm{O}-\mathrm{Mg}$ bonds. These results are consistent with the result shown in Figure 4(c). As new chemical bond of $\mathrm{Si}-\mathrm{O}-\mathrm{Mg}$ forms through the condensation reaction between colloidal silica (with $\mathrm{Si}-\mathrm{OH}$ on its surface) and magnesia after curing at $30^{\circ} \mathrm{C}$ for 24 hours, the demoulding strength of colloidal silica-bonded refractory castables increases with the addition of magnesia (shown in Figure 1)

The change in chemical bond of colloidal silica with and without magnesia was further investigated by FTIR. The FTIR spectra of colloidal silica with and without magnesia after curing at $30^{\circ} \mathrm{C}$ for 24 hours are shown in Figure 5 . It can be seen in the figure that the most intense peak at about $1115 \mathrm{~cm}^{-1}$ is assigned to the asymmetric $\mathrm{Si}-\mathrm{O}-\mathrm{Si}$ stretching vibration [18]; peaks at 1219 and $1068 \mathrm{~cm}^{-1}$ are attributed to the $\mathrm{Si}-\mathrm{O}$ stretching vibration $[18,19]$, a peak at $799 \mathrm{~cm}^{-1}$ results from the symmetric $\mathrm{Si}-\mathrm{O}$ stretching vibration, and peaks at 557 and $475 \mathrm{~cm}^{-1}$ are corresponding to the internal deformation of $\mathrm{Si}-\mathrm{O}[18,20-22]$, while the 

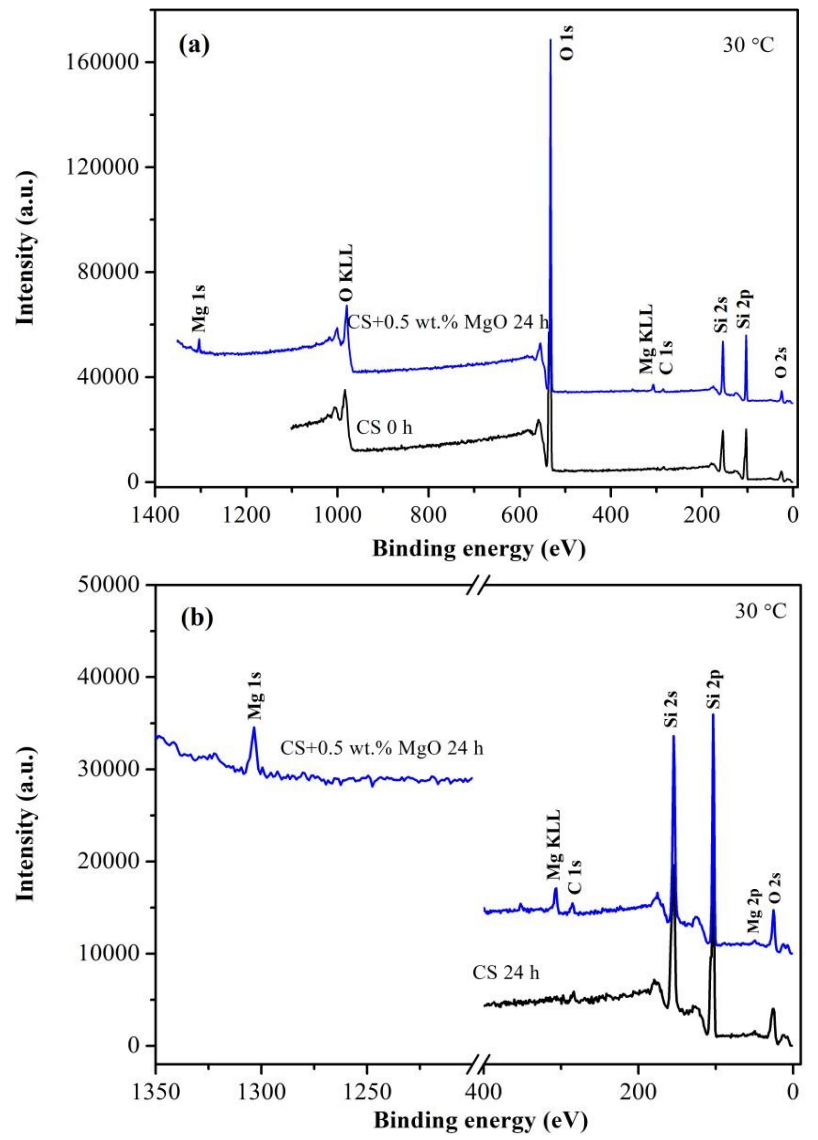

Figure 3: XPS spectra of colloidal silica with and without MgO after curing for 24 hours at $30^{\circ} \mathrm{C}(\mathrm{a})$, and (b) is a local amplification spectrum of (a).

$\mathrm{Si}-\mathrm{O}$ stretch of $\mathrm{Si}-\mathrm{OH}$ groups at the silica surface can be seen at $970 \mathrm{~cm}^{-1}$ [23]. As the the magnesia addition increased from $0.1 \mathrm{wt} . \%$ to $0.5 \mathrm{wt} . \%$, the spontaneous condensation of silanol groups has been enhanced through the incorporation of magnesia, because the intensity of the peak at $970 \mathrm{~cm}^{-1}$ (assigned to $\mathrm{Si}-\mathrm{OH}$ ) gradually decreases and eventually disappears in the FTIR spectrum of colloidal silica with 0.5 wt.\% magnesia (CS5). Similar trend can also be found in terms of peaks at 799 and 557 $\mathrm{cm}^{-1}$, which become weaker and even vanish as the magnesia addition increased from 0 to $0.5 \mathrm{wt} . \%$, revealing that $\mathrm{Si}-\mathrm{O}$ bonds have been partially broken by the introduction of magnesia [23].

Furthermore, the red-shift of characteristic $\mathrm{Si}-\mathrm{O}$ vibration from $475 \mathrm{~cm}^{-1}$ to $467 \mathrm{~cm}^{-1}$ suggests interaction between the $\mathrm{MgO}$ and silica [20, 24]. Because the binding force of $\mathrm{Mg}-\mathrm{O}$ is weaker than that of $\mathrm{Si}-\mathrm{O}$ and the $\mathrm{Mg}-$ $\mathrm{O}$ bond is longer than the $\mathrm{Si}-\mathrm{O}$ bond $[25,26]$, the partial replacement of $\mathrm{Si}^{4+}$ in $\mathrm{Si}-\mathrm{O}-\mathrm{Si}$ linkages by $\mathrm{Mg}^{2+}$ would lower the frequency around $475 \mathrm{~cm}^{-1}$. Therefore, the decreased wavenumber of $467 \mathrm{~cm}^{-1}$ (as shown in Figure 5b)
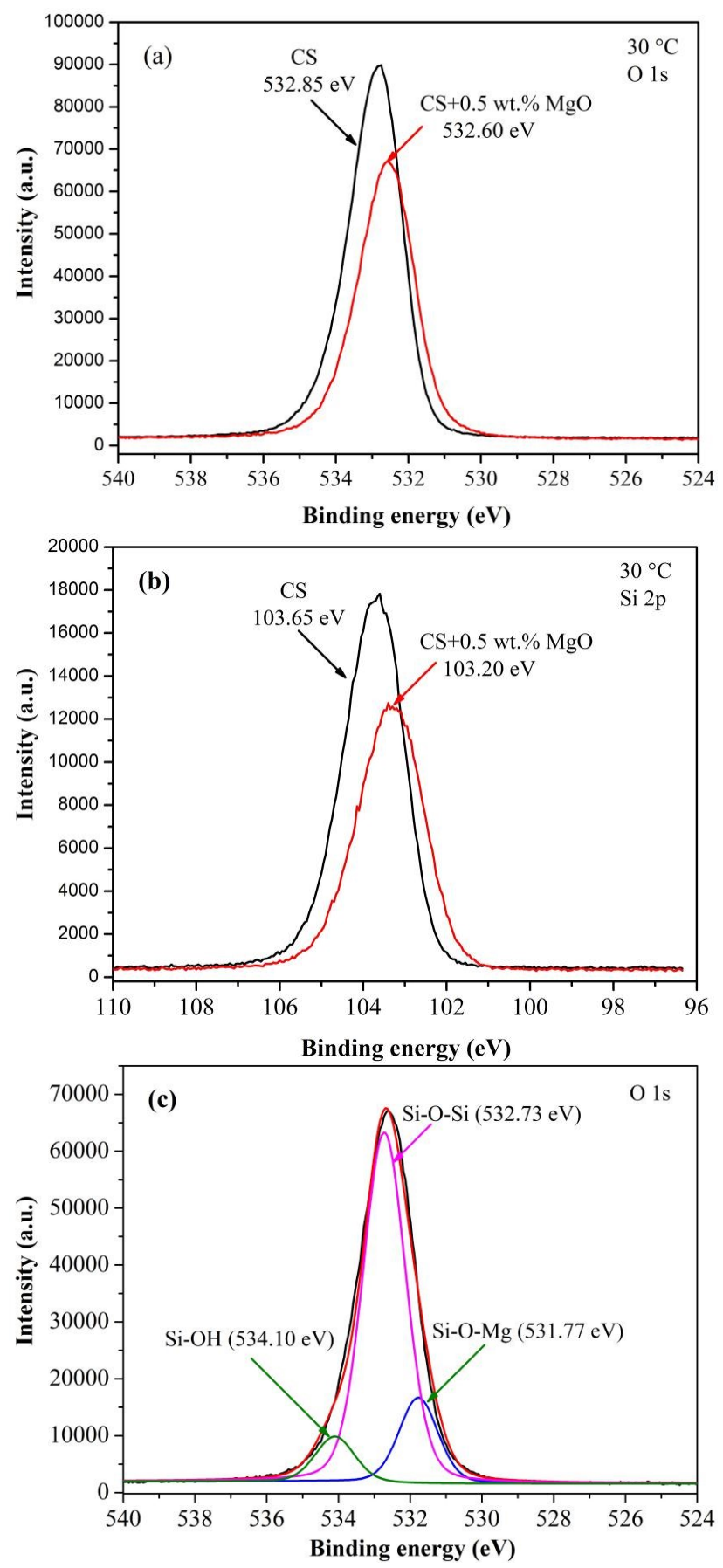

Figure 4: 0 1s (a) and Si 2p (b) XPS spectra for colloidal silica with and without magnesia, and the peak fitting of $01 s$ spectrum for colloidal silica with $0.5 \mathrm{wt} . \% \mathrm{MgO}$ (c).

in the colloidal silica with $0.5 \mathrm{wt} . \%$ magnesia is possibly caused by the incorporation of $\mathrm{Mg}^{2+}$ into the $\mathrm{Si}-\mathrm{O}-\mathrm{Si}$ linkages.

In particular, new peaks at 668 and $419 \mathrm{~cm}^{-1}$, which are attributed to the formation of $\mathrm{Si}-\mathrm{O}-\mathrm{Mg}$ bonds [2729] in colloidal silica with 0.3 wt.\% (CS3) and 0.5 wt.\% 

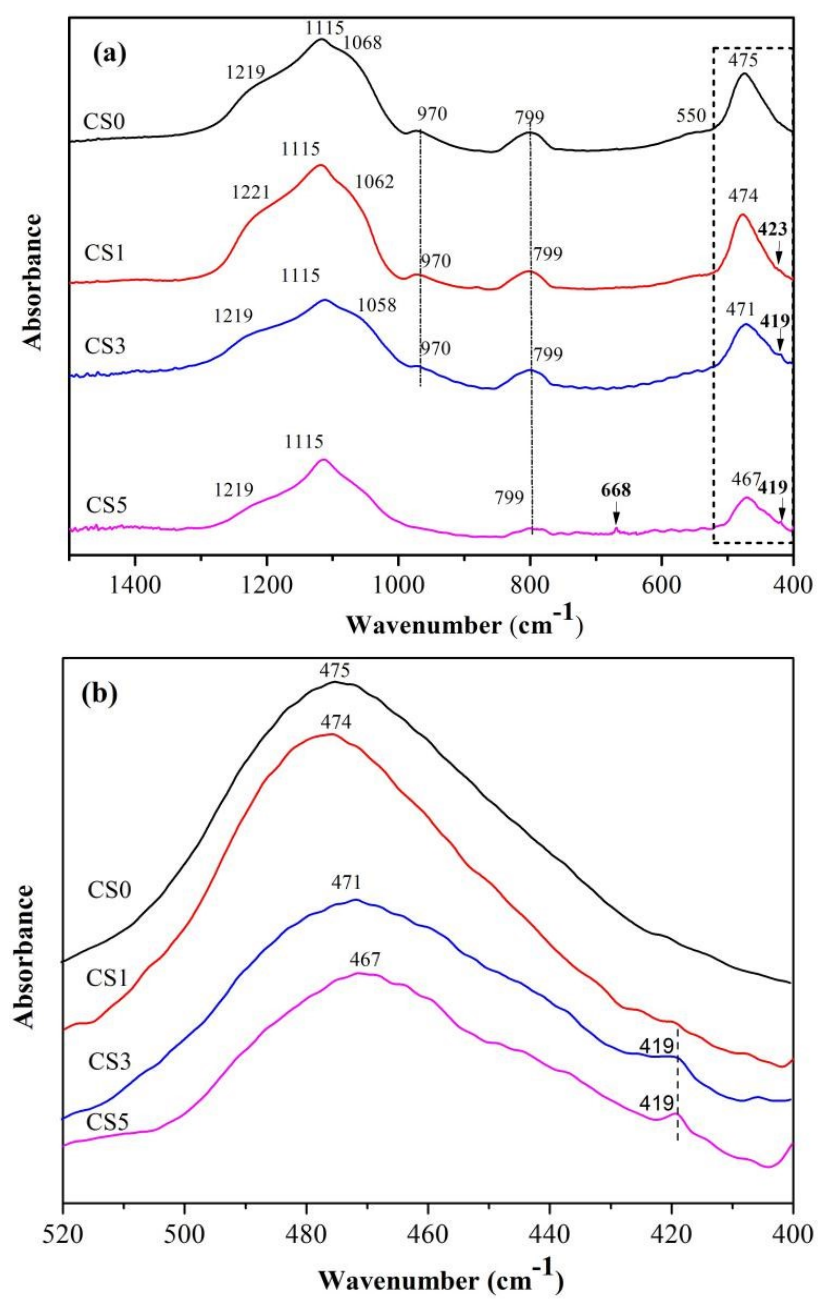

Figure 5: FTIR spectra of colloidal silica without and with 0.1-0.5 wt. $\% \mathrm{MgO}$ after curing for 24 hours at $30^{\circ} \mathrm{C}$ (a), and the magnification of FTIR spectra in the $520-400 \mathrm{~cm}^{-1}$ region (b).

(CS5) magnesia, can be observed in Figure 5(a). This phenomenon confirms that more amounts of $\mathrm{Si}-\mathrm{O}-\mathrm{Mg}$ bonds appear with the increase of magnesia addition. As described above, the enhanced condensation of colloidal silica with magnesia and the formation of $\mathrm{Si}-\mathrm{O}-\mathrm{Mg}$ bonds would provide higher demoulding strength of colloidal silica-bonded castables with magnesia after curing at $30^{\circ} \mathrm{C}$ for 24 hours.

\section{Conclusions}

The addition of magnesia enhanced the demoulding strength of colloidal silica-bonded castables with magnesia after curing at $30^{\circ} \mathrm{C}$ for 24 hours, due to the formation of $\mathrm{Si}-\mathrm{O}-\mathrm{Mg}$ bonds caused by the condensation reaction of colloidal silica with magnesia during the curing process. The formation of $\mathrm{Si}-\mathrm{O}-\mathrm{Mg}$ bonds in the mixture was verified by the decreased $\mathrm{O} 1 s \mathrm{BE}(532.60 \mathrm{eV})$ and $\mathrm{Si} 2 p \mathrm{BE}$ $(103.20 \mathrm{eV})$ in $\mathrm{Si}-\mathrm{O}-\mathrm{Mg}$ in colloidal silica with $0.5 \mathrm{wt} . \%$ magnesia, compared with $\mathrm{O} 1 \mathrm{~s} \mathrm{BE}(532.85 \mathrm{eV})$ and $\mathrm{Si} 2 p \mathrm{BE}$ $(103.65 \mathrm{eV})$ in $\mathrm{Si}-\mathrm{OH}$ after curing. Moreover, the formation of $\mathrm{Si}-\mathrm{O}-\mathrm{Mg}$ bonds in the mixture (CS5) was confirmed by new vibration peaks at 668 and $419 \mathrm{~cm}^{-1}$ corresponding to $\mathrm{Si}-\mathrm{O}-\mathrm{Mg}$ bonds after curing at $30^{\circ} \mathrm{C}$ for 24 hours.

Acknowledgement: The authors acknowledge National Natural Science Foundation of China (Contract No. 51572244, U1504526 and U1604252) for financial supports.

\section{References}

[1] M.R. Ismael, R. Salomao and V.C. Pandolfelli, Am. Ceram. Soc. Bull., 86 (2007) 58-61.

[2] M. Nouri Khezrabad, F. Arianpour, A. Talimian, F. Golestani Fard and N. Khalili, Refract. Appl. News., 11 (2006) 16-20.

[3] Q.L. Jia, J. Zhang, Y. Zhou, G.Y. Jia and X.H. Liu. Ceram. Int., 44 (2018), 3064-3068.

[4] M. Nouri-Khezrabad, M.A.L. Braulio, V.C. Pandolfelli, F. Golestani-Fard and H.R. Rezaie, Ceram. Int., 39 (2013) 34793497.

[5] R. D. dos Anjos, M.R. Ismael, I.R. de Oliveira and V.C. Pandolfelli, Ceram. Int., 34 (2006) 165-171.

[6] M. Nouri-Khezrabad, A.P. Luz, V.R. Salvini, F. Golestani-Fard, H.R. Rezaie and V.C. Pandolfelli, Ceram. Int., 41 (2015) 30513057.

[7] F.A. Cardoso, M.D.M. Innocentini, M.M. Akiyoshi and V.C. Pandolfelli, Refract. Appl. News., 9 (2004) 12-16.

[8] M.A.L. Braulio, G.G. Morbioli, J. Medeiros, J.B. Gallo and V.C. Pandolfelli. J. Am. Ceram. Soc., 95 (2012) 1100-1104.

[9] R.K. Iler, Wiley, New York: John Wiley \& sons, (1979).

[10] W.E. Lee, W.Vieira, S. Zhang, K.G. Ahari, H. Sarpoolaky and C. Parr, Int. Mater. Rev., 46 (2001) 145-167.

[11] M. Nouri-Khezrabad, A.P. Luz, F. Golestani-Fard, H.R. Rezaie and V.C. Pandolfelli, Ceram. Int., 40 (2014) 14523-14527.

[12] F. Azizian, Ceram. Ind., 147 (1997) 47-48.

[13] G.T. Ye and T. Troczynski, J. Mater. Sci., 40 (2005) 3921-3926.

[14] D. Chen, H.Z. Gu, A. Huang and Z.J. Shao, Ceram. Int., 43 (2017) 8850-8857.

[15] T.L. Barr, Zeolites., 10 (1990) 760-765.

[16] T.L. Barr, Appl. Surf. Sci., 15 (1983) 1-35.

[17] J.T. Kloprogge, L.V. Duong, B.J. Wood and R.L. Frost, J. Colloid Interface Sci., 296 (2006) 572-576.

[18] P. Pisciella and M. Pelino, J. Eur. Ceram. Soc., 25 (2005) 18551861.

[19] C. Wan and B. Chen, Nanoscale., 3 (2011) 693-700.

[20] D.R. M. Brew, P.P. Glasser, Cem. Concr. Res., 35 (2005) 85-90.

[21] M.Y. Huang, M.J. Zhang, D.J. Yao, X.C. Chen, Z.B. Huang and G.G. Yin, Ceram. Int., 43 (2017) 9583-9592. 
[22] H.C. Li, D.G. Wang, C.Z. Chen and H. Shi, Mater. Lett., 159 (2015) 459-462.

[23] J.R. Bailey and M.M. Mcguire, Langmuir., 2 (2007) 10995-10999.

[24] Y.H. Wang, B. Chi, C.L. Xiao, D.G. Chen, Y.J. Wang and M.H. Liu, Chem. Eng. J., 338 (2018) 628-635.

[25] M. Ishii, T. Shimanouchi and M. Nakahira, Inorg. Chim. Acta., 1 (1967) 387-392.
[26] G. Kovalchuk, A. Fernández-Jiménez and A. Palomo, Fuel., 86 (2007) 315-322.

[27] W.C. Yan, D. Liu, D.Y. Tan, P. Yuan and M. Chen, Spectrochim. Acta, Part A., 97 (2012) 1052-1057.

[28] M. Suárez and E. Garcia, Appl. Clay Sci., 31 (2006) 154-163.

[29] J. Cornejo and M.C. Hermosin, Clay. Miner., 23 (1988) 391-398. 